\title{
Taguchi optimisation of Turning Inconel 600 under dry and MQL condition using uncoated Tool
}

\author{
Kosaraju Satynarayana ${ }^{1, *}$, Aki Ruthwik $^{2}, S$ Siddhartha $^{2}, N V$ Dharma Teja ${ }^{2}, K S V$ Phanindra $^{2}$ and Kumkuma \\ Rajkiran $^{3}$
}

${ }^{1}$ Assoc.Professor, GRIET, Mechanical Engineering Department, Hyderabad, India. ${ }^{2}$ UG Student GRIET, Mechanical Engineering Department, Hyderabad, India. ${ }^{3}$ PG Student GRIET, Mechanical Engineering Department, Hyderabad, India.

\begin{abstract}
Utilization of super alloys have been prominent in production now-a-days to achieve a superior qualified high strength of low weight products. Advance trends have been performed in order to understand the impact of lubricating and cooling effects while turning these hard to cut alloy steels which produces tremendous amount of heat while machining. Present paper deals with one of those hard-to-cut alloys, Inconel 600 one of the hot working capable nuclear alloy. Turning experiments was performed using an carbide tool insert with varying rake angles $(-7,-5$ and -3 degrees), speed (50, 75 and $100 \mathrm{~mm} / \mathrm{min})$ and feed rate $(0.1,0.2$ and $0.3 \mathrm{~mm} / \mathrm{rev})$. A total of 9 experiments were performed based on the DOE. Surface roughness was measured and comparison of surface roughness is done for both dry and MQL conditions. In order to evaluate the optimum turning condition Taguchi optimisation was employed. It was observed that for dry turning rake angle at -3 degrees, speed at $50 \mathrm{~m} / \mathrm{min}$ and feed at $0.1 \mathrm{~mm} / \mathrm{rev}$ and rake angle at -3 degree, speed at $50 \mathrm{~m} / \mathrm{min}$ and feed at $0.3 \mathrm{~mm} / \mathrm{rev}$ for MQL turning was found to be optimum. A mathematical model for both the cases were also studied for turning operation.
\end{abstract}

\section{Introduction}

Super alloys are those which exerts high strength to low weight, high temperature with-standing ability, hot working condition, low oxidizing and low reactive material. Inconel 600 is one of such super alloy belonging to nickel chromium alloy. It has a stability to withstand its strength and properties at high temperatures. Inconel alloys have stability to withstand a temperature above $1000 \mathrm{C}[1]$. Due to the major amount of chromium of $13 \%-16 \%$ and nickel of $71-76 \%[2,3]$ in it, Inconel is proved to be noncorrosion alloy. Due to very low traces of ferrous in it, this alloy is non-magnetic by nature but exhibits high strength. It shows it mark of existence in aero-industries, nuclear industries, high precise engine manufacturing and ship building industries. Machining such high strength material is one of the biggest task for the production team [4]. Tool wear and high heat production are major draw backs that are estimated in cutting these alloys. In order to overcome these problems, tools machining such novel featured alloys are coated. Coating increases the tool wear and reduces the temperature evolved during machining them [5]. Built up edge (BUE) is also one of the undesirable property tool material in which the unwanted removed chip material gets welded over the tool. This is caused due to the high temperature generation at the cutting zone. This causes increase in surface roughness and stresses in materials. By coatings BUE can be overcome [6]. BUE also results in the increasing of residual stresses in the metal while machining. The generation of residual stresses in hard machining has been investigated by many researchers [79]. Surface roughness is one of the factor that tends quantifying the economical aspect of the product. Finer the surface finish the lesser the upcoming machining operation and the lower the wear and tear of the material. In this fact, precise surface roughness is to be expected as the outcome after the machining. Inconel 600 is one of the hard materials, so as per the standards negative rake angle must be adopted in machining these materials [10]. Machining of hard-to-cut materials have been carried out under high lubricating aids. Using of this high amount of lubricants in form of flooded lubrication systems shows its impact in both environmental, economic and human health. Recent trends have been showing a best solution to this problem. It is using Minimum quantity lubrication system or by cryogenic systems. Some researches claims that use of cryogenic fluids as lubricants reduces improves the machined parts when comparing to both dry and MQL machining systems[ [11], And also decreases the surface roughness [12]. But usage of cryogenics is not accepted in all the times as it needed highly controlled environmental conditions and high risk factor of operating them [13]. In 
view of this, present work is to study and optimize [14] the process parameters w.r.t roughness under dry and MQL turning with uncoated tools.

\section{Experimental details}

The turning experiments were carried out on a precision lathe setup (shown in Figure 1) using uncoated carbide cutting tools for the machining of Inconel 600 round rod, of dia $35 \mathrm{~mm}$ and length of $80 \mathrm{~mm}$. Uncoated carbide tool inserts, of ISO designation of CNMG 120408 along with applicable tool insert holder of PCLNR 2020 M.12 was used. DOE of L9 Taguchi orthogonal array tabulates with set of nine experimental work was chosen. Turning has been conducted with the process parameters, listen in Table 1.

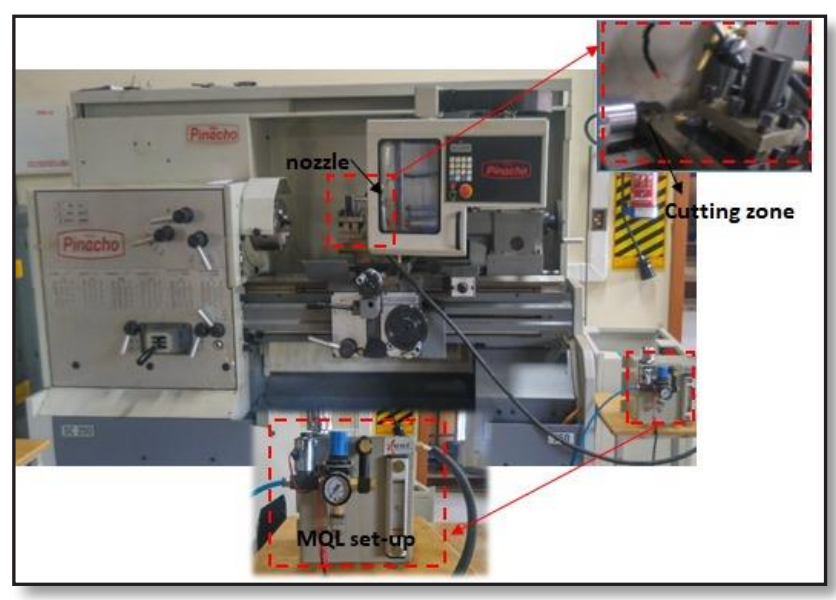

Fig. 1. Experimental Set-up

Table 1. Turning parameters and their levels

\begin{tabular}{|c|c|c|c|c|c|}
\hline Parameters & Designation & Units & Level 1 & Level 2 & Level 3 \\
\hline $\begin{array}{c}\text { Rake } \\
\text { angle }\end{array}$ & $\alpha$ & Degrees & -7 & -5 & -3 \\
\hline Speed & $\mathrm{v}$ & $\mathrm{mm} / \mathrm{min}$ & 50 & 75 & 100 \\
\hline Feed & $\mathrm{f}$ & $\mathrm{mm} / \mathrm{rev}$ & 0.1 & 0.2 & 0.3 \\
\hline
\end{tabular}

Combination matrix of machining parameters are shown in Table 2 which was formed by Taguchi L9 orthogonal array. The experimental results for the responses of $\mathrm{Ra}$ is also mentioned in the following table.. The surface roughness was the response variables of experimental values measured for both dry and MQL condition. The average surface roughness $(\mathrm{Ra})$, obtained on workpiece after first pass of machining with each tool, was measured with a portable surface roughness tester (Surf Test, SJ310, mitutoyo) selecting a cut off length of $0.8 \mathrm{~mm}$.

Table 2. L9 orthogonal array of the experimental runs and results

\begin{tabular}{|c|c|c|c|c|c|c|c|}
\hline \multirow{3}{*}{$\begin{array}{l}\text { Run } \\
\text { no. }\end{array}$} & \multicolumn{3}{|c|}{$\begin{array}{c}\text { Parameter } \\
\text { level }\end{array}$} & \multicolumn{2}{|c|}{$\begin{array}{l}\text { Experimental } \\
\text { results }\end{array}$} & \multicolumn{2}{|c|}{ S/N Ratio } \\
\hline & & & & Dry & MQL & Dry & MQL \\
\hline & $\alpha$ & $\mathrm{v}$ & $\mathrm{f}$ & $\begin{array}{c}\mathrm{Ra} \\
(\mu \mathrm{m})\end{array}$ & $\begin{array}{c}\mathrm{Ra} \\
(\mu \mathrm{m})\end{array}$ & $\begin{array}{c}\mathrm{Ra} \\
(\mu \mathrm{m})\end{array}$ & $\begin{array}{c}\mathrm{Ra} \\
(\mu \mathrm{m})\end{array}$ \\
\hline
\end{tabular}

\begin{tabular}{|l|l|l|l|c|c|c|c|}
1 & 1 & 1 & 1 & 0.568 & 0.489 & 4.913 & 6.214 \\
\hline 2 & 1 & 2 & 2 & 2.514 & 1.858 & -8.007 & -5.381 \\
\hline 3 & 1 & 3 & 3 & 4.08 & 3.647 & -12.213 & -11.238 \\
\hline 4 & 2 & 1 & 2 & 0.668 & 0.581 & 3.504 & 4.716 \\
\hline 5 & 2 & 2 & 3 & 1.851 & 1.69 & -5.348 & -4.557 \\
\hline 6 & 2 & 3 & 1 & 3.233 & 2.983 & -10.192 & -9.493 \\
\hline 7 & 3 & 1 & 3 & 0.619 & 0.34 & 4.166 & 9.370 \\
\hline 8 & 3 & 2 & 1 & 1.925 & 1.689 & -5.688 & -4.552 \\
\hline 9 & 3 & 3 & 2 & 2.86 & 2.471 & -9.127 & -7.857 \\
\hline
\end{tabular}

\section{Analysis of Results}

\subsection{Analysis of $\mathrm{S} / \mathrm{N}$ ratio}

In Taguchi method, the term 'signal' represents the desirable value (mean) for the output characteristic and the term 'noise' represents the undesirable value for the output characteristic. Taguchi concept of quality design is divided into three categories in the examination of the S/N (Signal to Noise) ratio, namely, LTB (lower-the-better), HTB (higher-the-better) and NTB (nominal the better). The LTB standard for the Surface roughness was chosen for acquiring optimum process parameters. The values of $\mathrm{S} / \mathrm{N}$ ratio were determined from the equation 1 using cutting force as $y_{i}$.

$$
\frac{S}{N}=-10 \log \left[\frac{1}{n} \sum_{k=1}^{n} y_{i}^{2}\right]
$$

Where, ' $\mathrm{n}$ ' is the number of tests and ' $y_{i}$ ' is the value of $F_{z}$ of the $i^{\text {th }}$ test.

The mean $\mathrm{S} / \mathrm{N}$ ratio for each level of the turning parameters can be computed by taking the average of each parameter at that particular level and listed in Table 3 and Table 4. As per the Taguchi method, highest value for $\mathrm{S} / \mathrm{N}$ ratio was preferred for optimizing the process parameters. Therefore, optimum condition for Ra during dry turning from Table 3 is $\alpha 3 v 1 \mathrm{fl}$ i.e., rake angle at -3 degrees, speed at $50 \mathrm{~mm} / \mathrm{min}$ and feed at $0.1 \mathrm{~mm} / \mathrm{rev}$ and in case of MQL turning is $\alpha 3 \mathrm{v} 1 \mathrm{f} 3$ i.e., rake angle at -3 degrees, speed at 50 $\mathrm{mm} / \mathrm{min}$ and feed at $0.3 \mathrm{~mm} / \mathrm{rev}$.

Table 3. S/N Response table for Ra during dry turning

\begin{tabular}{|c|c|c|c|c|c|c|}
\hline \multirow{2}{*}{ Level } & \multicolumn{3}{|c|}{ Dry Turning } & \multicolumn{3}{c|}{ MQL Turning } \\
\cline { 2 - 7 } & $\alpha$ & $\mathrm{v}$ & $\mathrm{F}$ & $\alpha$ & $\mathrm{v}$ & $\mathrm{f}$ \\
\hline 1 & -5.102 & $\mathbf{4 . 1 9 5}$ & $\mathbf{- 3 . 6 5 6}$ & -3.469 & $\mathbf{6 . 7 6 7}$ & -2.611 \\
\hline 2 & -4.012 & -6.348 & -4.543 & -3.111 & -4.830 & -2.841 \\
\hline 3 & $\mathbf{- 3 . 5 5 0}$ & -10.511 & -4.465 & $\mathbf{- 1 . 0 1 3}$ & -9.530 & $\mathbf{- 2 . 1 4 2}$ \\
\hline
\end{tabular}

\subsection{Regression Analysis}

The experimental results was processed to generate a mathematical model equation using cutting parameters of speed, feed rate, depth of cut and combined factors. It was generated using MINITAB 19 numerical statistic software. It is one of the primary tool analytical software module that is able to compute the regression values using the 
experimental outcome data. The equation generated with the regression coefficient of 0.90 for surface roughness was obtained with dry and MQL turning given in equation 2 and $3 \mathrm{~b}$ and also model summary.

For dry condition

$$
\begin{aligned}
\mathrm{Ra}= & 0.26+0.429 \text { rake angle }+0.0241 \text { speed } \\
& -3.80 \text { feed }-0.00567 \text { rake angle*speed } \\
& -0.751 \text { rake angle*feed }
\end{aligned}
$$

R-sq $=99.23 \%$ R-sq(Adj) $=97.75 \%$ R-sq(Pred $)=84.34 \%$

For MQL condition

$$
\begin{aligned}
\mathrm{Ra} & =1.260+0.4731 \text { rake angle }+0.0082 \text { speed } \\
& -6.52 \text { feed- } 0.00638 \text { rake angle* speed }-0.449 \\
& \text { rake angle*feed }+0.0472 \text { speed } * \text { feed }
\end{aligned}
$$

$\mathrm{R}-\mathrm{sq}=99.86 \% \mathrm{R}-\mathrm{sq}($ Adj $)=99.48 \% \mathrm{R}-\mathrm{sq}($ Pred $)=91.16 \%$

\subsection{Model Validation (Regression)}

The L9 orthogonal model with outcomes was verified by conducting a verification process for dry condition at $\alpha=$ 3 degrees $\mathrm{v}=50 \mathrm{~m} / \mathrm{min}$ and $\mathrm{f}=0.1 \mathrm{~mm} / \mathrm{rev}$ and for MQL condition at $\alpha=-3$ degrees $\mathrm{v}=50 \mathrm{~m} / \mathrm{min}$ and $\mathrm{f}=0.3 \mathrm{~mm} / \mathrm{rev}$

\begin{tabular}{|c|c|c|c|c|}
\hline Turning & $\begin{array}{l}\text { Optimum } \\
\text { condition }\end{array}$ & Experimentation & Model & $\begin{array}{c}\% \\
\text { Deviation }\end{array}$ \\
\hline Dry & $\begin{array}{c}\alpha=-3 \\
\text { degrees } \\
\mathrm{v}=50 \\
\mathrm{~m} / \mathrm{min} \text { and } \\
\mathrm{f}=0.1 \\
\mathrm{~mm} / \mathrm{rev}\end{array}$ & 0.551 & 0.496 & 9.89 \\
\hline MQL & $\begin{array}{c}\alpha=-3 \\
\text { degrees } \\
\mathrm{v}=50 \\
\mathrm{~m} / \mathrm{min} \text { and } \\
\mathrm{f}=0.3 \\
\mathrm{~mm} / \mathrm{rev}\end{array}$ & 0.391 & 0.362 & 7.18 \\
\hline
\end{tabular}
and reported in Table 5. It can be observed from the table that in percentage deviation of experimental and model found to be less than $10 \%$ which indicates that model is significant.

Table 5 comparison of experimentation and Model verification

\subsection{Analysis of Variance (ANOVA)}

The analysis was carried out using ANOVA optimization tool with $5 \%$ of level of significance ie.,for $95 \%$ of confidence level. The aim of using ANOVA optimization is to investigate the turning parameters that affects the performance outcomes characteristics [12]. Table 5 and 6 shows the results of ANOVA for Dry and MQL turning operation. It is observed from the table 5 and 6 that for machining Inconel 600 with uncoated tools under dry and MQL condition, the most significant contributing factor is rake angle ie., for dry turning $29.57 \%$ contribution and for MQL turning $41.85 \%$.
Table 5. ANOVA for Ra Dry turning

\begin{tabular}{|l|c|c|c|c|c|c|}
\hline \multicolumn{1}{|c|}{ Source } & DF & Adj SS & $\begin{array}{c}\text { Adj } \\
\text { MS }\end{array}$ & $\begin{array}{c}\text { F- } \\
\text { Value }\end{array}$ & $\begin{array}{c}\text { P- } \\
\text { Value }\end{array}$ & \%Cont \\
\hline Regression & 5 & 12.502 & 2.500 & 77.51 & 0.002 & \\
\hline rake angle & 1 & 0.180 & 0.180 & 5.60 & 0.099 & 29.57 \\
\hline Speed & 1 & 0.130 & 0.130 & 4.04 & 0.138 & 21.31 \\
\hline Feed & 1 & 0.051 & 0.051 & 1.61 & 0.294 & 8.47 \\
\hline $\begin{array}{l}\text { Rake } \\
\text { angle*speed }\end{array}$ & 1 & 0.168 & 0.168 & 5.23 & 0.106 & 27.61 \\
\hline $\begin{array}{l}\text { rake } \\
\text { angle*feed }\end{array}$ & 1 & 0.047 & 0.047 & 1.47 & 0.312 & 7.748 \\
\hline Error & 3 & 0.096 & 0.032 & & & 5.277 \\
\hline Total & 8 & 12.5991 & & & & 100 \\
\hline
\end{tabular}

Table 6. ANOVA for Ra MQL Turning

\begin{tabular}{|l|r|r|r|r|r|r|}
\hline \multicolumn{1}{|c|}{ Source } & DF & \multicolumn{1}{c|}{$\begin{array}{c}\text { Adj } \\
\text { SS }\end{array}$} & $\begin{array}{l}\text { Adj } \\
\text { MS }\end{array}$ & $\begin{array}{c}\text { F- } \\
\text { Value }\end{array}$ & $\begin{array}{c}\text { P- } \\
\text { Value }\end{array}$ & \%Cont \\
\hline Regression & 6 & 10.587 & 1.764 & 233.50 & 0.004 & \\
\hline rake angle & 1 & 0.171 & 0.171 & 22.62 & 0.041 & 41.85 \\
\hline Speed & 1 & 0.003 & 0.003 & 0.45 & 0.573 & 0.82 \\
\hline Feed & 1 & 0.082 & 0.082 & 10.89 & 0.081 & 20.14 \\
\hline $\begin{array}{l}\text { rake } \\
\text { angle*speed }\end{array}$ & 1 & 0.118 & 0.118 & 15.70 & 0.058 & \\
\hline $\begin{array}{l}\text { rake } \\
\text { angle*feed }\end{array}$ & 1 & 0.009 & 0.009 & 1.25 & 0.380 & 29.03 \\
\hline speed*feed & 1 & 0.016 & 0.016 & 2.15 & 0.280 & 3.97 \\
\hline Error & 2 & 0.015 & 0.007 & & & 1.85 \\
\hline Total & 8 & 10.602 & & & & 100 \\
\hline
\end{tabular}

\section{Conclusion}

This experimental data discussed the application of Taguchi method for optimizing the machining parameters in turning operation. As shown in the study, the Taguchi method provides an efficient and systematic methodology for the experimental design and optimization of machining parameters with far less effort that would be required for most optimization methodologies. Following conclusions can be drawn from the wok

1. The optimal combination of control factors for dry turning at -3 degrees rake angle, $50 \mathrm{~m} / \mathrm{min}$ cutting speed and $0.1 \mathrm{~mm} / \mathrm{rev}$ feed.

2. The optimal combination of control factors for MQL turning at rake angle at -3 degree, speed at $50 \mathrm{~m} / \mathrm{min}$ and feed at $0.3 \mathrm{~mm} / \mathrm{rev}$.

3. The models developed was verified and the results were predicted using the models. It show the good correlation with the surface roughness results.

4. Rake angle found to be most influencing parameter in both the cases using ANOVA analysis. 


\section{References}

1. Torres, A., I. Puertas, and C. J. Luis, The INT J ADV MANUF TECH 84.9-12 (2016)

2. Chandrasekar, G., C. Kailasanathan, and M. Vasundara. J. Manuf. Process, 35, 466-478 (2018)

3. Kulkarni, Anup, D. K. Dwivedi, and M. Vasudevan. J. Mater. Process. Technol. 274, 116280 (2019)

4. Beake, B. D., and G. S. Fox-Rabinovich. Int. Heat Treat. Surf. Eng, 5(1), 17-20 (2011).

5. Kitagawa, T., A. Kubo, and K. Maekawa. Wear 202(2), 142-148 (1997)

6. Y.S. Liao, R.H. Shiue, Wear 193, 16-24 (1996)

7. Srinivasa Rao D, Sandhya Rani MN, Sarfaraz Nawa z Syed and Suresh Kumar Tummala, E3S Web of Conferences 8701003 (2019)

8. C.R. Liu, S. Mittal, Wear 219, 128-140 (1998)

9. Kosaraju, Satyanarayana, M. Vijay Kumar, and N. Sateesh. Material Today 5, 2 5343-5348. (2018)

10. Ohbuchi, Y., and T. Obikawa. J. Eng. Mater. Technol. 125.3, 324-332 (2003)

11. Tummala Suresh Kumar, Kosaraju Satyanarayana, Materials Today: Proceeding, 26 (2), 2020.

12. Kaynak Y, Lu T, Jawahir IS. MACH SCI TECHNOL, 18(2), 149-198 (2014)

13. Pusavec F, Hamdi H, Kopac J, Jawahir I S.J MATER PROCESS TECH, 211(4),773-783 (2011)

14. Satyanarayana, Kosaraju, Anne Venu Gopal, and Popuri Bangaru Babu., IJMMM. 13(2-3), 191-202. (2013) 